\title{
Análise do Movimento em Rituais Umbandistas ${ }^{1}$
}

\author{
Marielle Kellermann Barbosa \\ José Francisco Miguel Henriques Bairrão² \\ Universidade de São Paulo - Campus Ribeirão Preto
}

\begin{abstract}
RESUMO - A presente pesquisa teve como objetivo fazer a análise do movimento em rituais umbandistas e, dessa forma, contribuir para o conhecimento da sua linguagem corporal, assim como fornecer subsídios para o desenvolvimento de uma etnopsicologia brasileira. Para efeito de análise, foi utilizado o método Laban, que visa analisar, segundo elementos de esforço, a movimentação corporal, assim como a tonicidade muscular, em relação ao peso, tempo, espaço e fluência. Foram examinados registros em vídeo de diversas classes de "espíritos" do panteão umbandista. A análise dos movimentos peculiares às diversas classes de "espíritos" mostrou que elas diferenciam-se umas das outras por padrões que as caracterizam em relação aos elementos de esforço analisados. Concluiu-se ser possível utilizar o método Laban para discriminar categorias do panteão umbandista e, dessa forma, acrescer o conhecimento a respeito da linguagem corporal nesse culto.
\end{abstract}

Palavras-chave: análise do movimento; etnopsicologia; psicologia e religião; umbanda; linguagem corporal.

\section{Movement Analysis in Umbanda Rituals}

\begin{abstract}
The purpose of this research is analyzing the movement in umbanda rituals in order to contribute for the knowledge of its corporal language, as well as supplying subsidies for the development of a Brazilian ethnopsychology. For the effect analysis, Laban method was used, which aims to analyze the effort elements of the corporal movement, as well as the muscles tonicities, in relation to the weight, time, space and fluency. Registers in video of many classes of "umbanda spirits" had been examined. The analysis of the peculiar movements of many "spirits" classes showed that they differentiate ones of the others for standards that characterize them in relation to the analyzed elements of effort. It was concluded that it is possible to use Laban method to discriminate categories of umbanda's "spirits" classes and in such way to increase the knowledge regarding the corporal language in this cult.
\end{abstract}

Key words: movement analysis; ethnopsychology; psychology and religion; umbanda; corporal language.

Ritos de possessão são uma oportunidade ímpar para se observar a articulação dinâmica e fundamentalmente corporal entre memória cultural e o presentemente vivenciado (Stoller, 1995). Segundo Farnell, "Nossa capacidade imaginativa não é meramente indiretamente corpórea, desde que as metáforas, metonímias e imagens são baseadas na experiência corporal" (Farnell, 1999, p. 359). Nessa medida, para devidamente se proceder ao estudo do movimento, é fundamental especificar um contexto sócio-cultural da sua consideração, o qual, no caso deste artigo, é a umbanda, religião genuinamente nacional (Concone, 1987).

\section{Corpo e linguagem na umbanda}

"A religião umbandista fundamenta-se no culto dos espíritos e é pela manifestação destes, no corpo do adepto, que ela funciona e faz viver suas entidades" (Ortiz, 1978, p. 69). $\mathrm{O}$ autor acresce que

O universo umbandista opera essencialmente com quatro gêneros de espíritos que são os modelos de toda e qualquer individualidade espiritual. A cada estereótipo corresponde

1 Apoios FAPESP e CNPq. Agradecemos aos membros do grupo de pesquisa do Laboratório de Etnopsicologia da Faculdade de Filosofia Ciências e Letras da USP-RP, pelas contribuições motivacionais, teóricas e trabalho de campo.

2 Endereço: Av. Bandeirantes, 3900. Bairro: Monte Alegre, SP, Brasil 14040-901.E-mail: jfbairrao@ffclrp.usp.br um número infinito de entidades particulares, possuindo, cada qual, uma personalidade própria, que se identifica pelo nome (Ortiz, 1978, p. 76).

No entanto, ele mesmo reconhece que "Não existe uma classificação espiritual unanimemente aceita pelos teóricos" (p. 78). Além dos quatro tipos tradicionais a que se refere (exus, crianças, caboclos e pretos-velhos), nesta pesquisa foram considerados outros três (marinheiros, boiadeiros e baianos) e versões femininas de três deles (pomba-giras, caboclas e baianas), todos muito freqüentes nos terreiros e bastante característicos do ponto de vista da sua movimentação. Tem sido apontado que os espíritos da umbanda podem encarnar estereótipos literários: "Os caboclos podem ser vistos como representações estereotipadas do bom selvagem e os preto-velhos do escravo fiel" (Brown, 1994, p. 69).

A "umbanda não é só religião; ela é um palco do Brasil" (Prandi, 1991, p. 88). Conforme as vicissitudes históricas do país e os dramas sociais enfrentados pelas classes populares, surgem novas ou se redefinem antigas "linhas" do panteão (Bairrão, 2004). Cada uma dessas "linhas" de espíritos se associa tipicamente a cenários naturais cuja interpretação, muitas vezes misturada a lendas de santos católicos, é feita com base em mitos dos orixás africanos. Brumana e Martinez (1991) apontam que "As entidades umbandistas não são criações 'ex nihilo' do culto, e sim a absorção de elementos preexistentes em diversos registros culturais" (Brumana \& Martinez, 1991, p. 257), e agregam que o universo umban- 
dista expressa um "microcosmo da sociedade brasileira" (p. 143). A propósito dos rituais de possessão na umbanda, acrescentam que:

Estas entidades "baixam em terra" em cerimônias quase sempre públicas, realizadas várias vezes por semana tanto nos terreiros como em lugares escolhidos por suas características simbólicas, cemitérios, praias, florestas, etc... Elas o fazem seguindo uma estrita codificação corporal, gestual e verbal, muitas vezes realçada por roupas características, objetos, comidas, bebidas, tabaco etc. (Brumana \& Martinez, 1991, p. 63).

Stoller (1995) critica diferentes formas pelas quais o fenômeno do transe foi tratado na literatura, entre elas a abordagem de Lewis (1971/2003), que vê o transe como revelador de estruturas sociais, e a psicanalítica, que ao enfatizar o médium, tende a ignorar a sua relevância social. Essas e outras abordagens, em particular as que o lêem, estabelecendo-o em analogia com um texto, deslocariam a supremacia ocidental do verbal para sociedades nas quais aspectos sensoriais são mais relevantes.

Diversos pais-de-santo entrevistados por Negrão (1996) contam que, muitas vezes, a experiência da mediunidade se inicia pela sensação física da entidade (espírito). Acontece o movimento interior como primeiro "sinal" de que algo está acontecendo, muitas vezes o médium relata não saber nada sobre umbanda ou sobre entidades, e que apenas posteriormente sua sensação física é significada por um pai de santo, como sendo pertencente a determinada entidade. Como é próprio dos rituais de possessão, na umbanda, a movimentação corporal se faz presente em termos de comunicação, pois por meio dela e da música, a entidade incorporada pelo médium se faz reconhecer (Rouget, 1980).

Muitos estudos foram feitos sobre a umbanda (entre outros, Brown, 1986/1994; Brumana \& Martinez, 1991; Concone, 1987; Montero, 1985; Negrão, 1996; Ortiz, 1978), bem como sobre outros cultos afro-brasileiros. Porém, pouco tem sido feito no sentido de observar e analisar sistematicamente a linguagem corporal existente nos seus rituais de possessão, salvo trabalhos como o de Rodrigues (1997) e o de Bárbara (2002).

A presente pesquisa objetivou verificar a possibilidade de, mediante o "método Laban", igualmente conhecido pela designação de "análise do movimento", descrever e discriminar as movimentações corporais típicas de 10 categorias de espíritos suscetíveis de "possuírem", em transe, médiuns umbandistas, no intuito de contribuir para o conhecimento da umbanda no atinente à sua linguagem corporal, assim como de levantar subsídios para uma etnopsicologia brasileira.

\section{O método Laban}

Coreógrafo e teórico da dança da primeira metade do século XX, Laban (1971/1978) inaugura em suas companhias e com os seus escritos uma forma de dança e da sua interpretação na qual deve transparecer, na performance do bailarino-ator, suas intenções e estados emocionais internos: "A fonte da qual devem brotar a perfeição e o domínio final do movimento é a compreensão daquela parte da vida interior do homem de onde se originam o movimento e a ação" (Laban, 1971/1978, p.11). Laban investiga de que maneira o corpo transmite estados internos, por movimentos, respiração e tensão muscular. Segundo ele, sentimentos, idéias ou estados de espírito são representados no movimento por meio do esforço. Este é o conjunto de impulsos internos dos quais se originam os movimentos, que podem ser vistos em maior ou menor reação muscular.

A tensão muscular, a velocidade do movimento, a maneira como é freado são nuanças de movimentação que podem ser apreendidas pelos quatro fatores de movimento previstos por Laban. "Esses elementos comportam a chave da compreensão daquilo que se poderia chamar o alfabeto da linguagem do movimento: e é possível observar e analisar o movimento em termos desta linguagem" (Laban, 1971/1978, p. 168). Tais fatores são: peso, tempo, espaço e fluência. Cada um é acompanhado por uma participação interna (espécie de atitude diante de). No que se refere ao fator de movimento peso, a participação interna é a intencionalidade; no caso do tempo é a decisão; no caso do espaço é a direção; e no caso da fluência é a progressão. É importante ressaltar que os elementos de esforço são conceitos específicos, que dizem respeito a características intrínsecas à movimentação (e que podem ser ativos ou passivos em relação ao fator de movimento).

Observa-se o elemento de esforço peso perguntando que grau de energia muscular é gasto no movimento. Quão resistente este movimento é ao próprio peso da pessoa que se movimenta, à gravidade, e dessa questão surgem dois tipos de respostas: o movimento pode ser firme, isto é, resistente ao peso, com uma atitude intencional ativa em relação a ele e na interação com o espaço, apresentando tensão muscular. Outra possibilidade é o movimento apresentar-se passivo em relação ao peso, e essa atitude abre a possibilidade de dois tipos de movimento: o leve e o relaxado. Laban coloca essas duas características como fazendo parte do elemento de esforço peso leve, porém, acreditamos ser importante fundamentar a conceituação desse elemento de forma a diferenciar claramente ambos. Um tipo de movimento é aquele que não se opõe, não resiste ao peso e por isso é leve. Podemos pensar, por exemplo, em uma pena, que cai levemente porque não tem "peso" (na acepção do senso comum) e não resiste nem a ele (pois não o tem) e nem ao ar. Outro tipo de movimento que não resiste ao peso é o movimento relaxado, o que chamaríamos na linguagem comum de "pesado". Um corpo de um homem morto sendo carregado não resiste em nada ao peso, mas ao contrário de ser leve, é relaxado, abandonado ao seu próprio peso. Podemos pensar então, que o movimento não resistente ao peso é leve quando não "pesa" (como a pena), quando não apresenta densidade corporal. Mas que é relaxado, abandonado, quando tem densidade, o que não passa a sensação de leveza, mas de ser "pesado".

Observa-se o elemento de esforço tempo perguntando qual a velocidade do movimento, qual a duração deste. O movimento pode ter uma atitude ativa ou passiva em relação ao tempo. A atitude ativa em relação ao tempo cria um movimento de tempo súbito, passando a sensação de acontecer de repente, em um instante. Por sua vez, a atitude passiva diante do tempo cria um movimento de longa duração, o que dá a sensação de um movimento longo, infinito. Observa-se o fator de movimento espaço na maneira como o movimento chega ao lugar para onde houve o deslocamento. Se ele chega de forma direta, quer dizer que tem uma atitude ativa 
em relação ao espaço, se a atitude é passiva, o movimento é flexível em relação ao espaço.

O elemento de esforço fluência caracteriza a progressão que o movimento tem, se ele é fluido ou controlado. O movimento controlado é ativo em relação à sua progressão, existe interferência na fluência, o que passa a sensação de algo entrecortado, como por exemplo, o tremor de mãos ou pernas. Entretanto, o movimento livre é passivo em relação à fluência, passando a sensação de continuidade e liberdade. É importante ressaltar que os elementos de análise (peso, tempo, espaço e fluência) não são categorias estanques, mas estão intimamente relacionados, o que confere maior complexidade ao tratamento dos resultados, ao mesmo tempo em que privilegia a idéia de continuidade da movimentação e preserva a característica não mecanicista da análise.

\section{Método}

O "corpus" do trabalho constituiu-se de um acervo préexistente de gravações audiovisuais de rituais umbandistas. Entre esses registros, foram selecionados vídeos nos quais médiuns em transe apareciam movimentando-se, incorporados por "espíritos" pertencentes a categorias do panteão, comuns e bem estabelecidas. Tal recorte referenciou-se em Negrão (1996) e, quando isso se evidenciou relevante, adotou-se a subdivisão de algumas em função da variável gênero. Foram analisados, em média, 20 vídeos de cada classe considerada (exus, pomba-giras, pretos-velhos, caboclos, caboclas, baianos, baianas, marinheiros, boiadeiros e crianças). Buscou-se ter diversidade de terreiros e médiuns, para que o corpus pudesse, da melhor maneira, ser fidedigno ao objetivo do trabalho.

Não é possível abarcar toda a gama de diferenças e vicissitudes do universo dos movimentos nas danças rituais da umbanda, e nem foi esse o objetivo do estudo. Visou-se a observar e analisar a movimentação mais típica de algumas categorias, não perdendo de vista o que muito nos escapará. A análise seguiu uma gradação na categorização dos fatores de movimento, entre pouco e muito. A gradação do pouco ao muito é referente às próprias classes de entidades, portanto essa valoração foi sendo dada ao longo do processo de análise.

Em congruência com o pensamento de Birman (2005), a presente pesquisa focou todo o corpus de análise a partir da perspectiva dos sujeitos, referindo aos espíritos as performances corporais, pois é assim que os umbandistas as compreendem. Segundo Laban, não é possível analisar a complexidade do movimento e dos diversos significados corporais apenas pela observação exterior, tese reafirmada por Farnell no campo da antropologia: "Ironicamente, talvez o que faça do movimento corporal físico uma ação humana não seja visível. (...) Ações, em oposição ao comportamento, não podem ser compreendidas apenas pela observação" (Farnell, 1999, p 359).

É, portanto, fundamental que o estudioso se aproprie de seu corpo como instrumento de pesquisa e forma de compreensão do seu objeto de estudo (Stoller, 1995) e, para tanto, um dos autores utilizou-se da sua experiência como bailarina para vivenciar os movimentos e, dessa maneira, perceber o tipo de esforço feito em cada caso.

\section{Resultados}

\section{Exus}

Movimentam-se de maneira peculiar, forjando no corpo algo que traz à memória lembranças de monstros de histórias infantis no momento de suas transformações ou aqueles homens enclausurados por feitiços destinados a dividir o mesmo corpo com uma besta.

$\mathrm{Na}$ incorporação do exu, transparece mais que nas outras categorias a presença do esforço, aquele movimento interno anterior ao movimento mais visível e aparente. No momento da incorporação, aparece um movimento semelhante ao que igualmente surge na incorporação de outras entidades, caracterizado pelo tremer do tronco e braços e pelo aparente "empurrão" para trás que o médium sofre, fazendo-o perder o equilíbrio. O tremor do corpo, mais especificamente do tronco, parece irradiar de dentro para fora, como se o movimento começasse no centro do peito e se espalhasse pelos ombros, cotovelos, braços e mãos. Na parte inferior do corpo, esse tremor irradia como fraqueza nas pernas, que acabam por tombar à força do exu que está chegando. $\mathrm{O}$ exu, por vezes, parece arrastar-se. Muitas vezes movimenta-se próximo ao chão, quase ajoelhado, com o tronco encurvado, os braços para trás e as mãos retorcidas, por vezes tensas. Outras vezes, aparece andando, mas geralmente com o tronco curvado. Os exus mexem o pescoço de maneira peculiar, por vezes, assemelhando-se ao movimento de um cachorro, outras vezes ao de um pássaro. Aparecem também mexendo os ombros de forma a sacudi-los, pesados e fluidos.

Negrão (1996) traz depoimentos de pais de santo que relatam que quando os exus chegam ao terreiro não se levantam e andam como bichos, mas, à medida que vão ajudando as pessoas e "evoluindo", passam a caminhar em pé. O encurvamento corporal dos exus equivaleria à sua tortuosidade moral e, de acordo com a sua "elevação" moral, seu corpo passaria a ficar ereto.

Relativamente aos exus, o fator de movimento preponderante é o peso (intencionalidade). São intensamente "pesados" (muito relaxados). O caminhar dos exus, seja em pé, seja com a ajuda dos joelhos, não tem tensão muscular, não resiste ao peso, é passivo diante do seu corpo, que parece ter um "peso" grande. É "pesado", no sentido de abandonar-se ao peso, relaxado, sem resistência. O mesmo se pode dizer a respeito do tronco e dos braços. São relaxados e não resistentes; abandonados ao seu próprio e grande peso. As mãos que se retorcem atrás do corpo podem seguir esse padrão de movimento "pesado" mas solto, e geralmente apresentam tensão muscular forte, resistente.

Em relação ao fator espaço, podemos observar que o caminhar e a movimentação do tronco e dos braços dos exus têm direção definida, não se estendem pelo espaço enquanto trajetória (por exemplo, seus passos "buscam” o chão). Essa característica de espacialização parece um pouco indefinida no caso dos exus, porque eles não têm a característica do elemento peso firme, o que dá a impressão de não terem retidão nos movimentos. Mas o têm à sua maneira, com o peso abandonado, relaxado. Portanto, relativamente ao fator de movimento espaço, a sua movimentação tem a característica de ser pouco direta. 
No que concerne ao elemento tempo, podemos observar que a movimentação dos exus tende a ser um pouco lenta. Não passa a sensação de um tempo indefinido, mas de maneira nenhuma é algo que acontece apenas em um curto momento. Como praticamente não dançam, a análise da fluência dos movimentos é dificultada, visto que temos que observar apenas seu andar e os movimentos do tronco, braços e cabeça.

\section{Pomba-giras}

Segundo Negrão (1996), "se o Exu é em parte animalesco, a Pomba-Gira é a estereotipia da prostituta ou de mulheres de conduta moral condenável" (Negrão, 1996, p. 223). Talvez essa conotação moral negativa derive da circunstância de uma atitude social bastante crítica da sensualidade explícita, que efetivamente caracteriza o movimento corporal dessa categoria. Entre as estudadas, as pomba-giras são a categoria de espíritos que mais se mostra no corpo de forma dançante e transparece prazer nesse dançar. Em seus rostos, há constantemente uma expressão de alegria e divertimento, sorriem e dão gargalhadas enquanto dançam. Elas dão gargalhadas, movendo o tronco e a cabeça para trás. Flexionam os joelhos um pouco para possibilitar o movimento do tronco, com as mãos apoiadas na altura dos ossos pélvicos. Fumam de maneira a deixar, algumas vezes, a mão que segura o cigarro com o pulso virado, a mão "caída", dando a impressão de uma mulher sensual, extrovertida e desinibida. Caminham, passando o peso do corpo todo (seu ponto de equilíbrio) de uma perna para a outra, com um movimento de quadril como se o peso deste fosse solto sobre a perna que está dando o passo. Podemos, portanto, observar o fator de movimento peso como estando presente de forma relaxada, deixando o movimento sem resistência àquele.

A pomba-gira anda rebolando, com as mãos apoiadas na altura do quadril, o que deixa os braços dobrados. Seu caminhar é lento no que tange ao fator de movimento tempo. Porém, quando dança pode girar em uma velocidade maior. Apóia, para caminhar, os pés inteiros no chão. O quadril mexe junto com os passos e os braços apoiados no quadril movem-se também, sem resistir ao movimento natural do corpo todo. Seu andar transborda sensualidade explícita, que parece não perder nenhum espaço do corpo em que possa apresentar-se.

Quando as pomba-giras dançam, elas costumam girar com um pé apoiado inteiro no chão e outro apoiado no metatarso (meia ponta). Elas costumam utilizar-se de movimentos de ombro, por vezes discretos, e por outras definidos. Seus ombros podem tanto mover-se acompanhando o movimento dos braços, que se movem por estarem apoiados nos quadris que se mexem pelo caminhar, quanto fazer-se acompanhar de movimentos mais fortes, quando, por exemplo, dão gargalhadas. Mas, nos dois momentos, os ombros movem-se por irradiação de outros movimentos (um pelo caminhar e o outro pelo movimento do tronco durante a gargalhada).

As pomba-giras não resistem ao peso, não têm tonicidade muscular para serem ativas em relação a ele. Elas se abandonam inteiramente às ondas de movimento que o andar, o gargalhar, ou o parar, trazem. Quando elas param, por exemplo, param "molinho". O quadril se ajeita sobre uma perna, os braços no quadril, o ombro de acordo com os braços e, assim, o corpo todo se acomoda, parecendo obedecer à lei de mínimo esforço. Nem suas mãos, apoiadas pelo dorso no quadril de forma a encaixarem-se, fazem força. Essa sensação de movimento "mole" parece ser dada pela junção do fator de movimento peso relaxado, não resistente, ao de espaço flexível. Seus movimentos não apresentam retidão, direcionamento, mas trajetória, caminho. A fluência é livre, a movimentação das pomba-giras tem um fluxo contínuo, é passiva em relação a esse elemento de esforço.

\section{Marinheiros}

Os marinheiros são considerados espíritos de homens que morreram no mar e vêm cambaleando, pelo balanço das ondas ou por estarem bêbados. Presentificam-se no corpo por uma movimentação típica de um homem que parece não ter equilíbrio e dá passos desajeitadamente, para não cair. Caminham perdendo e recuperando o equilíbrio a todo o momento. Dão passos rápidos de forma a alcançar o corpo que já fora previamente lançado a outro ponto, sem o deslocamento das pernas. Parecem lançar o peso do corpo (principalmente pelo tronco) para fora de seu ponto de equilíbrio e, para não cair, "correm" a fim de alcançar onde o tronco está. Segundo Laban:

No domínio do movimento, o equilíbrio instável desempenha importante papel. Este tipo de equilíbrio acontece quando o centro de gravidade tende a alterar sua relação vertical normal com o ponto de suporte.

Podem-se observar freqüentemente coordenações especiais de ações corporais, no ser humano, com a finalidade de contrabalançar a perda do equilíbrio ou de recuperá-lo. (Laban, 1971/1978, p. 102).

Essas coordenações especiais com a finalidade de restabelecer o equilíbrio perdido são claramente observadas nos marinheiros e constituem sua característica de movimento mais marcante. Quando parados, os marinheiros usualmente mantêm as pernas afastadas uma da outra, de forma a parecer que usam dessa disposição para manter-se no mesmo lugar, visto que seu equilíbrio não é estável. Mesmo quando parados, eles balançam o tronco e podem estar amparados em outra pessoa. Seus braços têm uma movimentação que parece descontrolada, solta ao próprio peso, parecendo ser este o que direciona o movimento.

Suas pernas podem tanto aparecer com os joelhos flexionados, o que passa a sensação de um corpo sem tonicidade, sem firmeza, quanto com estes esticados, passando a impressão de falsa firmeza, visto este estiramento denunciar certa falta de controle. $\mathrm{O}$ tronco e a cabeça dos marinheiros parecem, na maior parte das vezes, acompanharem o andar cambaleante ou o precederem, visto ser o deslocamento deles que cria a necessidade de movimentação das pernas.

A partir dessas considerações podemos observar o movimento dos marinheiros como sendo caracterizado pelo fator de movimento peso relaxado. Eles não resistem ao peso, não apresentam tonicidade muscular de resistência, muito pelo contrário, abandonam-se a ele e parece ser esse o principal motor de toda a sua movimentação, já que esta não parece acompanhar exatamente a intencionalidade voluntária. Em relação ao fator de movimento espaço, os marinheiros são flexíveis. Seus movimentos passam a sensação de não seguirem 
uma linha ou terem retidão. Sua movimentação tem fluência controlada, seus passos e movimento dos braços e cabeça não são livres na sua fluência, são entrecortados. O movimento do marinheiro é passivo diante do elemento de esforço tempo. A participação interna diante desse fator é a de decisão, atitude esta que os marinheiros não parecem apresentar em sua movimentação, por caracterizar-se como cambaleante, passando assim a sensação de ser descontrolada, aleatória à sua decisão.

\section{Baianos}

"Se o Caboclo é a seriedade e o Preto-Velho é a serenidade, o Baiano é a alegria e, mais que isso, o deboche" (Negrão, 1996, p. 216). Tidos como brincalhões e festeiros, os Baianos são muito populares. Caracterizam-se pela movimentação peculiar de seus pés e pernas. Caminham e dançam como se estivessem dançando baião, embora possam aparecer em alguns terreiros sem essa característica tão marcante. O baião a que nos referimos, que os baianos parecem dançar, é a dança na qual se mantêm os braços para trás, as mãos dadas uma à outra na altura do quadril e faz-se movimentos de maneira a um pé permanecer atrás, marcando o tempo, enquanto o outro movimenta-se de um lado para o outro mais à frente. O peso permanece no pé de trás, enquanto o outro pé pontua o chão, fazendo um apoio rápido.

Nesse movimento de pontuar o chão com o pé, o tronco dos baianos permanece ereto, mas um pouco encurvado. Podem manter os dois braços para trás ou apenas um, enquanto o outro se mantém solto à frente ou flexionado na altura do peito. Seu pescoço parece acompanhar o movimento "pontuante" do corpo, mexendo-se de maneira livre e leve. O pé que vai à frente pode tanto apoiar-se no chão por inteiro quanto apenas no calcanhar, mantendo a ponta do pé levantada. Os baianos são leves, no referente ao fator de movimento peso. Eles não lhe resistem. A sensação de leveza passada pela movimentação dos baianos se dá talvez pela junção do peso leve com os fatores espaço direto e tempo súbito. Os movimentos dos baianos têm fluência controlada. É como se o movimento fosse entrecortado ativamente, não fluindo livremente.

\section{Baianas}

A característica que mais diferencia as baianas é o balançar das saias. Elas dançam muito e na maioria das vezes balançam a saia com as mãos. Seguram as pontas da saia e as mexem para frente e para trás ao redor do corpo. Dançam, muitas vezes, com um dos pés apoiado no chão apenas pela meia ponta e o outro apoiado inteiro, transferindo o peso de um pé para o outro. A dança das baianas é "macia" e fluente. No que se refere ao fator de movimento peso, a movimentação das baianas é leve, não resistente. Elas não parecem ter uma atitude ativa em relação ao peso do corpo, nem em seu pisar no chão nem em sua tonicidade muscular.

A dança das baianas é marcada pelo elemento de esforço ativo em relação ao espaço. Sua movimentação é direta e definida, como se o movimento tivesse "para onde ir". Em relação ao tempo, sua movimentação tem velocidade um pouco rápida. Não se trata do caso de serem movimentos súbitos, mas de acontecerem em um curto espaço de tempo.
Elas fazem movimentos livres em relação à fluência, o que significa deixar que eles sigam sua fluência natural, sem controlá-la. Portanto, têm como fator de movimento fluência o elemento de esforço livre.

\section{Boiadeiros}

Os boiadeiros caracterizam-se principalmente por fazerem o movimento de "laçar" com um dos braços. Esse movimento caracteriza-se por um movimento circular com a mão e com o cotovelo na mesma direção, porém em tempos diferentes. A mão que faz o movimento geralmente o faz acima da cabeça, enquanto o outro braço pode manter-se apoiado na cintura ou solto, enquanto a mão estala os dedos. Esse movimento com os braços, característico do boiadeiro, apresenta o fator de movimento peso pouco firme, já que mostra tensão muscular e resistência ao peso, mas sem dar a sensação de um movimento extremamente tenso. O caminhar dos boiadeiros apresenta a mesma linha de resistência ao peso, pouco firme. Resiste ao chão e ao peso do corpo, tem firmeza, mas não o faz de forma a passar a sensação de um movimento tenso. Podemos dizer que o boiadeiro encontrase em um ponto mediano na linha entre a firmeza e a leveza, deslocado para a extremidade do movimento firme.

Pode aparecer como movimento característico dos boiadeiros o corpo inteiro movimentando-se como se estivesse a cavalgar, os dois braços semi-flexionados como em um movimento de subida e descida, passando a idéia de estar segurando rédeas; e os pés levantando os calcanhares ritmadamente. A forma de caminhar e a disposição dos pés não são muito bem definidas, um pode estar apoiado inteiramente no chão e o outro apoiado pela meia-ponta ou ambos apoiados inteiramente no chão, realizando um caminhar lento com o deslocamento de um pé após o outro e mantendo as pernas um pouco afastadas. $\mathrm{O}$ fator de movimento tempo define-se por um elemento de esforço ativo. Existe atitude ativa em relação ao tempo (decisão). Caracteriza-se como pouco súbito. O movimento de "laçar" caracteriza-se pelo fator de movimento espaço flexível. Não existe busca de determinado ponto no espaço durante o movimento. Ele estende-se flexivelmente, o que se visualiza no movimento circular da mão e do cotovelo.

Em relação ao fator de movimento fluência, pode-se dizer que a movimentação tanto das pernas e pés quanto dos braços e mãos dos boiadeiros é pouco livre. Não existe atitude ativa em relação à fluência, deixando-a livre para acontecer, porém não é uma liberdade total. Existe certo controle, mas aproxima-se mais de um movimento livre.

\section{Pretos-velhos}

Os pretos-velhos movimentam-se tal e qual um homem muito velho e encurvado, que treme as pernas e freqüentemente apóia os braços ou um braço na coxa, deixando o outro atrás das costas, parcialmente parado. Caminham com os pés inteiramente apoiados no chão, mantêm a cabeça baixa e estalam os dedos de uma das mãos. Andam vagarosamente e logo se sentam, parecendo cansados. Seu andar é firme. Utilizam forte energia muscular nas pernas, o que passa a sensação de tensão, de cansaço e de dificuldade em locomo- 
ver-se. Seu tronco, braços e cabeça seguem o mesmo padrão de tensão muscular, passando a impressão de um corpo rígido. Os braços ou um braço, dependendo do médium e do terreiro, apóiam-se na coxa, repetindo a força com que os pés e pernas pressionam o chão. A cabeça permanece baixa.

A movimentação do preto-velho não é fluida. Seus passos são entrecortados de maneira a darem a impressão quase de tremores. Suas pernas tremem contraditoriamente, porque não têm força e, dessa maneira, tensionam-se. "Se se pára completamente o fluxo de ações corporais, resulta uma posição. Se o fluxo for interrompido intermitentemente, produz-se um tipo trêmulo de movimento" (Laban, 1971/1978, p. 89). A única movimentação realmente característica do preto-velho é o seu caminhar, visto que o tronco, a cabeça e os braços apenas apóiam-se nas pernas e seguem esse caminhar sem terem movimento independente. Esse caminhar é direto, no que tange ao fator de movimento espaço. Os passos têm retidão e direção definida, mas esse fator de movimento não se apresenta com intensidade, ele é pouco direto em relação ao espaço.

O movimentar-se do preto-velho não é rápido, mas também não se pode dizer que seja lento. Não passa a sensação de infinito ao longo do tempo em que acontece. Podemos dizer que o elemento tempo não é marcado em sua movimentação, e que parece pouco definido em relação ao elemento peso (bastante característico do movimento do preto-velho) e ao elemento fluência. Ao observarmos o preto-velho locomover-se, podemos pensar em um movimento lento, visto que seu andar é vagaroso, mas é importante lembrar que o elemento de análise tempo não coincide com a noção de tempo cronológico. Não analisamos quanto tempo o corpo leva no deslocamento, mas qual é a duração interna do movimento em si mesmo (a vivência temporal do gesto, se acontece instantaneamente ou se passa a impressão de perdurar indefinidamente).

\section{Crianças}

As crianças têm uma forma peculiar de movimentar-se, específica e diferente de todas as outras classes de espíritos. Elas se movimentam, caminham e dançam, como se fossem crianças pequenas "estilizadas", no sentido de fazerem movimentos exagerados, maiores do que uma criança real faria. Muitas crianças engatinham, usam chupetas, sentam-se com as pernas esticadas (o que requer flexibilidade, que na maioria das vezes o adulto não tem mais) ou com os joelhos dobrados (de "borboletinha"). Batem palmas, passando a impressão de uma criança muito alegre e excitada. Balançam o tronco e mais ainda a cabeça, de um lado para o outro. Uma característica interessante da movimentação das crianças é sua falta de acompanhamento do ritmo da música. Todas as outras entidades que dançam o fazem, o que auxilia a passar a impressão de uma criança "de carne e osso".

Quando as crianças dançam, batem palmas e pulam descoordenadamente em relação à música e com vivacidade, passando a impressão de alegria e excitação transbordantes do corpo. Geralmente não ficam em pé por muito tempo. Ficam sentadas e arrastam o corpo para movimentar-se. Têm uma movimentação livre, no sentido de não apresentar padrão. Engatinham, ficam deitadas, rolam no chão, pulam, pegam nos pés, balançam o tronco, brincam, levantam os braços etc., o que indica um corpo em movimento que ainda não foi "domesticado" pelos hábitos culturais.

Em relação ao fator de movimento peso, as crianças são relaxadas. Não lhe apresentam resistência. Não têm tonicidade muscular rígida nem usam o chão de maneira a resistirem à gravidade, mas o seu movimento não é leve, não passa a sensação de não ter peso. Pelo contrário, ao movimentaremse, as crianças usam o peso a favor de seus movimentos, parece ser ele quem leva seus braços, que faz seu corpo cair sentado. Porém, diferentemente dos exus, das pomba-giras e dos marinheiros, as crianças movimentam ativamente seu "peso relaxado", pulam com força, batem palmas, caem sentadas, arrastam-se, carregando seu peso, que existe, mas que é usado a favor do movimento.

As crianças fazem movimentos controlados. Interrompem-nos bruscamente, não os deixando livres para percorrerem sua fluência normal. Em relação ao espaço, elas fazem movimentos flexíveis, sem direção definida, sem parecer buscar determinado lugar. Pelo contrário, passam a sensação de serem caóticos no que se refira a chegar a algum lugar.

\section{Caboclos}

O caboclo apresenta regularmente uma movimentação específica no primeiro momento da incorporação. Ele apóia um dos joelhos no chão, dobrando uma perna e mantendo a outra esticada, curva o tronco para o lado e quase apóia o quadril no tornozelo da perna que está dobrada. Cruza os braços batendo no peito com força, mantém as mãos fechadas, ou semi-fechadas, fazendo a forma de um "L" com o dedo indicador e o polegar esticados. Costuma gritar durante esse movimento. Porém há grandes variações desse movimento inicial. Alguns caboclos apenas batem com os braços cruzados no peito, outros batem e encostam-nos no chão e alguns fazem o movimento de lançar uma flecha, como se estivessem esticando a corda de um arco.

Esse primeiro momento, dramático em sua encenação, é marcado pela força dos braços que batem no peito, passando a sensação de tensão muscular nesse movimento, acompanhado pela força da voz, o que sugere a imagem de um guerreiro. Essa movimentação é marcada pelo elemento de esforço ativo em relação ao espaço, dando-lhe a característica de ser direto. Os braços batendo cruzados no peito têm uma direção certeira, assim como a posição das pernas, uma dobrada, a outra estendida, têm direções bem definidas. Esse movimento tem uma curta duração, acontece em um espaço de tempo curto. Passado o primeiro momento da incorporação, o médium costuma levantar-se e mantém freqüentemente a posição das mãos semi-fechadas, fazendo a forma de um " $L$ " com o indicador e o polegar esticados.

Uma característica física marcante do caboclo é a sua expressão facial. Frequientemente o médium torce a boca para baixo, fazendo com que seus olhos e testa acompanhem esse movimento, o que passa a impressão de um rosto sério. Podemos apreender dessa expressão facial o elemento de esforço peso, no que se refere à tensão muscular necessária ao rosto para manter a expressão "dura" do caboclo. O caboclo caminha e gira com um pé apoiado inteiro no chão e outro apoiado no metatarso. O pé apoiado no metatarso fica em posição de meia-ponta e costuma ficar um pouco atrás do 
outro pé. Todo o caminhar do caboclo é marcado pela movimentação de trocar o peso de um pé todo apoiado no chão para outro semi-apoiado, o que lhe confere um "balançar" de todo o corpo, tanto para a frente como para trás (de um pé para o outro) quanto para cima como para baixo (pela diferença de altura entre um pé e outro).

O exagero desse movimento pode criar a impressão de um coxear, como se o caboclo carregasse uma das pernas. Diferentemente dessa significação de aleijamento, que pode ser sugerida por essa imagem de caminhar "balançante", a análise "por dentro" dos elementos de esforço revela a possibilidade de um movimento fluido e firme. Esse caminhar que balança é marcado pela sensação de peso, de resistência ao chão, de firmeza. Mas diferentemente do caminhar pesado dos preto-velhos, é fluido. Essa fluência é também dada pela disposição dos pés, que possibilita o balançar do corpo em um movimento resistente mas contínuo. Tal sensação de movimento pesado e resistente não é intensa. O movimento do caboclo caracteriza-se como de uma firmeza moderada.

Os caboclos costumam andar e girar com a disposição de pés acima descrita e apresentam amplo repertório de movimentação com os braços. Às vezes mantêm os braços cruzados nas costas, outras os levantam pelos cotovelos, pelos ombros, também podem cruzar os braços acima da cabeça ou girá-los no ar. A postura do tronco do caboclo também é variada, mas costuma manter certa retidão, a qual o pescoço e a cabeça acompanham. $\mathrm{O}$ caboclo sempre dança e caminha ereto, com a cabeça alinhada ao tronco, olhando para frente.

\section{Caboclas}

As caboclas movimentam-se de forma marcadamente distinta da dos caboclos. Elas dançam bastante e podem fazêlo com muitas variações, dependendo da "linha" (variação, subtipo) à qual pertencem. Analisaremos aqui as caboclas das águas, por serem as que mais se diferenciam, em termos de linguagem corporal, dos caboclos. As caboclas movem-se elegantemente. Sua movimentação transborda sutileza e feminilidade, a qual, porém, pouco se parece com a sensualidade explícita das pomba-giras. Quando dançam ou andam parecem flutuar, não ter peso. Portanto, em relação ao fator de movimento peso, têm uma atitude passiva, fazendo movimentos leves.

Apresentam movimentação separada dos quadris, como só elas e as pomba-giras o fazem, mas de maneira totalmente diferente. Se a pomba-gira rebola e seu quadril tem o padrão do resto de seu corpo, relaxado, "pesado", a movimentação dos quadris das caboclas é mais sutil, menos acentuada e leve. Seus pés não se apóiam totalmente no chão e esse apoio parece passar despercebido, de tão leve. Seus braços se movem bastante, seguindo esse padrão de movimento sutil, delicado, talvez dado pelos elementos de esforço passivo em todos os fatores de movimento. Seu peso é leve, sua velocidade (tempo) é lenta, o espaço no qual seu corpo se move é flexível e existe fluência total (liberdade) em seus movimentos.

\section{Discussão}

Os elementos de esforço combinados parecem funcionar como uma percepção gestáltica, a soma das partes produz uma realidade nova, visto que os fatores de movimento
- peso, tempo, espaço e fluência - são interdependentes e modificam-se uns aos outros. A caracterização de movimento das caboclas: leve, lento, flexível e livre, é descrita por Laban (1971/1978) como uma movimentação flutuante, que ele chama de "A deusa". Todos os elementos de esforço são passivos, complacentes. Se, em termos de movimentação, as caboclas são (para Laban) "deusas", as pomba-giras também o são. As suas movimentações apenas divergem pelo fator de movimento peso das primeiras caracterizar-se por ser muito leve e o das segundas, muito relaxado. As caboclas parecem deslizar no ar, não "pesar" (no sentido comum), ao contrário das pombas-giras, que mostram o peso (valor) do corpo.

Quase diametralmente oposta aos movimentos das caboclas é a caracterização de movimento dos caboclos: firme, súbito e direto, dito por Laban como um movimento de soco. Os caboclos apresentam atitude ativa diante de três dos quatro fatores de movimento. Enquanto o "casal" caboclo-cabocla se diferencia em quase todos os fatores de movimento, o baiano-baiana se assemelha em três deles e em apenas um (fluência) é diferente, exatamente naquele em que caboclos e caboclas se identificam. A demarcação de gênero pelo movimento, portanto, pode assinalar-se na umbanda de maneiras bastante diferentes, até simetricamente opostas. Se, em linhas gerais, a atitude passiva em relação aos diversos fatores de movimento caracterizar o feminino e a atitude ativa o masculino, podemos considerar o casal cabocla-caboclo como sendo o extremo dessa demarcação de gênero. Porém, é importante não compreender os fatores de movimento como mera somatória, perdendo de vista o cunho gestáltico da combinação dos mesmos. Os marinheiros, por exemplo, têm em três dos fatores de movimento elementos de esforço passivo, o que não significa pouca masculinidade. Distinguem-se da "deusa" pomba-gira em um único elemento de análise e isso é suficiente para produzir um tipo bastante distinto (nenhum umbandista jamais os confundiria).

Não obstante por uma perspectiva puramente visual parecerem bastante distintos, de certa forma os marinheiros aproximam-se dos exus, distinguindo-se fundamentalmente no quesito espaço, diretividade (flexíveis os primeiros e pouco diretos os segundos) e pela diluição da preponderância do fator peso. Os marinheiros também apresentam fatores de movimento diametralmente opostos aos dos caboclos. Médiuns, pais e mães de santo referem-se aos caboclos como sendo sérios e morais, e aos marinheiros como galanteadores e beberrões (Negrão, 1996). Podemos cogitar que tal contraposição, do ponto de vista das qualidades "psicológicas" e "comportamentais" projetadas nesses espíritos, possa de alguma maneira aparecer na oposição das qualidades da movimentação corporal entre essas duas categorias, sendo os caboclos firmes, súbitos, diretos e livres e os marinheiros relaxados, lentos, flexíveis e controlados.

Entre os caboclos e os boiadeiros, o único fator de movimento que se modifica é o espaço. Quando o elemento de esforço torna-se passivo em relação ao espaço, o movimento de soco (característico dos caboclos) transforma-se em movimento de "talhar", já que a direção fica difusa (Laban, 1971/1978). Isso pode ser observado no movimento dos boiadeiros, já que sua movimentação mais típica é a do "laçar", que se assemelha ao que Laban chama de "talhar". Enquanto os boiadeiros fazem um movimento (flexível) com os braços 
como se "puxassem" uma corda, os caboclos o fazem como se lançassem uma flecha (direto).

Os exus e pomba-giras são tidos como categorias espirituais que refletem valores terrenos e qualidades materiais. Desse pólo também se aproximam os marinheiros, não obstante a sua índole "aquática". Essas três classes de espíritos movimentam-se relaxada e lentamente, no que tange aos fatores peso e tempo. Essa combinação entre não resistir ao peso e fazer movimentos lentos parece compor um tipo de movimentação arrastada, "pesada" (no sentido comum do que é pesado), estabelecendo um nexo entre o simbolismo existente no meio umbandista e a experiência corporal com essas entidades. Em relação a essas categorias, os baianos inovam nos quesitos peso (leve) e tempo (súbito), ou seja, intencionalidade e decisão.

No sentido da atitude ativa em relação ao peso, temos os pretos-velhos e os caboclos (e até certo ponto os boiadeiros) com movimentos firmes, resistentes. Nesse caso, de entidades "elevadas" na topografia simbólica umbandista, o peso não parece articular-se significantemente com a idéia de movimento pesado, mas com um domínio do "chão", capacidade de realização e aptidão para o real. Não fosse pelo quesito peso, em que se opõem drasticamente, a movimentação dos pretos-velhos e a dos exus seria similar. Estes se "abandonam" ao peso e os primeiros simbolizam uma assimilação sábia da experiência da vida, "resistente" ao seu "peso".

É surpreendente como uma das classes de espíritos ditas das mais celestiais no panteão, as crianças, se apresenta corporalmente com o peso relaxado, como as entidades mais terrenas. Mas, entre as categorias que têm a característica de serem relaxadas, as crianças são a única a ter atitude ativa em relação ao tempo, o que pode conferir essa sensação de que seu peso relaxado não "atrasa" os movimentos, mas, pelo contrário, é utilizado de maneira a fazê-los acontecer.

As crianças "não têm pernas", segundo relatos de pais e mães de santo, e por isso não podem ficar em pé. Pode-se cogitar uma metaforização de crianças pequenas que ainda não tenham aprendido a andar e aventar a hipótese de que "ter pernas" significa um estado de maturidade, de domínio do "material", de competência para se mover, "resistindo" ao peso. Recorde-se que os pretos-velhos, a mais "madura" de todas as categorias (aquela em que os espíritos se representam como velhos), praticamente só têm pernas (o resto do corpo acompanha o movimento delas). Poderia-se ainda especular que as categorias mais terrenas submeter-se-iam à força da gravidade e que as crianças seriam suficientemente "estranhas" à força da terra para padecerem da falta de tônus muscular ("espiritual") que lhes permitiria equilibrarem-se em pé e serem resistentes ao peso.

Nessa linha, é possível cogitar que segmentos corporais em combinação com características de movimento, no transe umbandista, codifiquem e literalmente corporifiquem significações religiosas, encarnem e modulem significações e compreensões não-verbais.

\section{Conclusão}

Uma crítica recorrente às abordagens tradicionais de estudo da possessão tem sido a de não levarem em conta aspectos sensoriais irredutíveis ao privilegiamento do olhar exterior (da observação) e da palavra (do verbal) na nossa cultura ocidental e científica. Por outro lado, é impossível reconstruir o corpo de saberes psicológicos inerente a práticas culturais como os ritos de possessão (uma tarefa legítima da etnopsicologia) sem alguma concepção do que seja o psíquico e modelos para a sua análise que possibilitem o estudo contrastivo. O fato da "análise do movimento" de Laban visar um estudo dos modos como o corpo transmite estados internos (sentimentos, idéias ou estados de espírito, nas suas palavras), compreendidos em termos de reações de esforço muscular, torna-a uma potencial candidata à satisfação dessas duas condições.

Com esta pesquisa, confirmou-se a possibilidade de utilizar o método Laban para analisar a movimentação corporal das classes de espíritos selecionadas, categorizando-as e diferenciando-as segundo os quatro fatores de movimento propostos por Laban. Foi possível caracterizar e discriminar as categorias entre si, evidenciar vínculos, correlações e contraposições entre elas. A "análise do movimento" permitiu sondar sensações, elementos de esforço e sentidos corporais de maneira não redutora ao verbal, o que é fundamental, pois larga parte da experiência religiosa umbandista, se não a mais importante, é vivida, sentida e compreendida corporalmente.

Mais do que isso, encontraram-se evidências de ser possível combinar os resultados desse tipo de análise com saberes sobre o contexto sócio-religioso umbandista obtidos por outros métodos para levantar o véu de presumíveis significações não-verbais manifestas nos rituais, enunciadas corporalmente e matizadas por um colorido histórico-cultural brasileiro.

Por meio da idéia de esforço, o movimento pode ser compreendido em seu contexto, o que possibilita um olhar etnopsicológico para a experiência corporal de possessão na umbanda, experiência apenas acessível pelo transe, por meio do corpo, e não pela mera observação exterior. Esse olhar "incorporado" pode vir a abrir portas para futuras análises e melhor compreensão do universo umbandista.

\section{Referências}

Bárbara, R. (2002). A Dança das Aiabás. Tese de Doutorado, Universidade de São Paulo, São Paulo.

Bairrão, J. F. M. H. (2004). Sublimidade do Mal e Sublimação da Crueldade: Criança, Sagrado e Rua. Psicologia: Reflexão e Crítica, 17(1), 61-73.

Birman, P. (2005). Transas e transes: sexo e gênero nos cultos afrobrasileiros, um sobrevôo. Estudos Feministas. Florianópolis, 13(2), 256.

Brown, D. D. (1994). Umbanda: religion and politics in urban Brazil. New York: Columbia University Press. (Trabalho original publicado em 1986)

Brumana, F. G. \& Martinez, E. G. (1991). Marginália Sagrada. Campinas: Editora da Unicamp.

Concone, M. H. V. B. (1987). Umbanda, Uma Religião Brasileira. São Paulo: CER/EDUSP.

Farnell, B. (1999). Moving Bodies, Acting Selves. Annual Reviews in Anthropology, 28, 341-373.

Laban, R. (1978). Domínio do Movimento. São Paulo: Summus Editorial (Trabalho original publicado em 1971) 
Lewis, I, (2003). Ecstatic Religion: A Study of Shamanism and Spirit Possession (3 3 ed.). London/New York: Routledge. (Trabalho original publicado em 1971)

Montero, P. (1985). Da doença à desordem: a magia na umbanda. São Paulo: Graal.

Negrão, L. N. (1996). Entre a Cruz e a Encruzilhada. São Paulo: Edusp. Ortiz, R. (1978). A morte branca do feiticeiro negro. Petrópolis: Vozes.

Prandi, R. (1991) Os candomblés de São Paulo: a velha magia na cidade nova. São Paulo: Hucitec.

Rodrigues, G. (1997). Bailarino Pesquisador Intérprete. Rio de Janeiro: Funarte.
Rouget, G. (1980). La Musique et La Transe: esquisse d'une théorie générale des relations de la musique et de la possession. Paris: Gallimard.

Stoller, P. (1995). Embodying Colonial Memories: Spirit Possession, Power and the Hauka in West Africa. Londres: Routledge.

Recebido em 23.02.2007

Primeira decisão editorial em 24.07.2007

Versão final em 23.08.2007

Aceito em 29.09.2007 